\title{
Medical training in the European Community
}

\author{
A.H. Crisp* \\ St. George's Hospital Medical School, Cranmer Terrace, London, SW17 ORE, UK.
}

\begin{abstract}
Summary: The free movement of doctors within the European Community demands harmonization of standards of medical practice and carries major implications of an undergraduate and postgraduate educational kind. These have begun to be addressed by the first three Medical Directives and also by a series of reports produced by the Advisory Committee on Medical Training to the European Community. This Committee was established in 1975 in order to provide informed agreed advice to the Commission. Many tasks remain to be tackled. A system of mutual inspection of the examination processes and standards in Member States should be established. Control must also be exercised over the numbers of doctors produced since educational resources, including numbers of patients available for study, are limited. Thus, excellent standards of medical practice can only be developed and maintained if the primacy of clinical skills derived from the study of patients is recognized as essential in this respect. In some Member States at the present time there are many unemployed and therefore presumably deskilled doctors.
\end{abstract}

\section{General introduction}

A Guide to Working in Europe without Frontiers which is the goal of many for 1992 has recently been published by the Commission of the European Communities. ${ }^{1}$ I will begin by paraphrasing its introductory statement about our rights as nationals of the Community's Member States. The European Community (EC), previously the European Economic Community (EEC), is governed by law wherein we enjoy rights as a national of a Member State. As migrants within it we are entitled to freedom of movement. This is one of the most important basic principles of the Common Market (Article 3 (c) of the EEC Treaty) which is based on equal treatment with nationals of the host country. In other words we cannot be discriminated against on the grounds of nationality (Article 7 of the EEC Treaty). The host country must respect all the implications of this principle. In return we are legitimately subject to the same obligations as nationals in the host country. We have a duty to prepare for this, mainly through some form of training. The Community is making a contribution to this process, particularly through implementation of the European Community action scheme for the mobility of university students (The ERASMUS Scheme).

Correspondence: Professor A.H. Crisp., M.D. D.Sc., F.R.C.P., F.R.C.P. (E)., F.R.C.Psych.

*Professor Crisp was Chairman of the Advisory Committee on Medical Education to the EEC, 1983-1986.
Equal treatment by a host country within the Community concerns occupational activity, certain social and political rights, freedom of movement and the right to transfer funds. We are concerned here today with occupational activity. There are certain exceptions to the general rule regarding equal eligibility for employment. For instance, posts in the judiciary, police, armed forces or diplomatic service and in goverment administration may be reserved for nationals. However, doctors and others in allied professions to medicine are eligible without discrimination on grounds of nationality. A distinction, however, is made according to whether you are an employed person (Article 48 of the EEC Treaty) or a self-employed person (Articles 52 and 59 of the EEC Treaty). If you are employed by others as a medical practitioner, then your terms of employment (professional qualifications, pay, conditions governing dismissal and Trade Union membership) are the same as those for nationals. If you are a selfemployed doctor you may also pursue your activity in any Member State, either on a permanent or temporary basis. However, you must also possess

We are grateful to the Editor of the European Journal of Internal Medicine, Professor U. Carcassi, for permission to publish this article from European Journal of Internal Medicine (1990) 1: 180-192.

The Fellowship of Postgraduate Medicine is also grateful to Wyeth Laboratories for financial support for this publication as a contribution to postgraduate medical education. 
the professional qualification attested by a diploma, certificate or other evidence of formal qualification awarded by the host state or recognized as equivalent by that state and recognized as necessary for such medical practice.

Article 57 of the original EEC Treaty states in its first paragraph:

In order to make it easier for persons to take up and pursue activities as self-employed persons, the Council shall, on a proposal from the Commission and in cooperation with the European Parliament, acting unanimously during the first stage and by a qualified majority thereafter, issue directives for the mutual recognition of diplomas, certificates and other evidence of formal qualifications.

Since that time the machinery for such harmonization has slowly developed. It has not yet fully addressed all professions, e.g. architecture. However, where there are such Community Directives adopted by the Council, then Member States recognize relevant diplomas issued for the purposes of employment by the Member States. While these provisions apply both to individuals in paid employment and to the self-employed, they do not concern all occupations. They also contain arrangements which may vary depending on the occupation in question, e.g. concerning the use of a particular title issued on the completion of training. When diplomas are recognized at Community level at the same time, a minimum required standard of qualification is established and, for each occupation, recognition depends on the extent to which standards have been harmonized. Accordingly, several situations may be encountered.'

1. Based on harmonization of training conditions.

2. Without harmonization of training conditions, e.g. architecture.

3. Combined with work experience (This was urged by some Member States).

So far as medicine is concerned, practice within other Member States is governed by the recognition of diplomas based on harmonization of training conditions. For instance, for doctors, nurses, dentists, veterinary surgeons, midwives and pharmacists a diploma is recognized provided it was issued in accordance with the Directives and has the same effects as diplomas issued by that Member State. This effect is achieved through the harmonization of training in the Member States and in the case of medicine this is through the initial medical Directives and which have led to reciprocal recognition of the relevant diplomas issued by the various Member States.

\section{The first medical directives}

Medical practice was one of the first professions to be addressed. Working parties comprising relevant groups of professionals from the Member States at that time were assembled and they advised on the form of the first two medical Directives. These were promulgated in June 1975. The first of these Directives (75/362/EEC) concerned the mutual recognition of diplomas, certificates and other evidence of formal qualifications in medicine and included measures to facilitate the effective exercise of the right of establishment and freedom to provide services. It addressed itself to both undergraduate and postgraduate education and the pivotal articles are Article 2 and Article 4 respectively. Article 2 states:

Each Member State shall recognize the diplomas, certificates and other evidence of formal qualifications awarded to nationals of Member States by other Member States in accordance with Article 1 of Directive No 75/363/EEC and which are listed in Article 3 , by giving such qualifications, as far as the right to take up and pursue the self-employed activities of a doctor is concerned, the same effect in its territory as those which the Member State itself awards.

Article 4 states:

DIPLOMAS, CERTIFICATES AND OTHER EVIDENCE OF FORMAL QUALIFICATIONS IN SPECIALIZED MEDICINE COMMON TO ALL MEMBER STATES

Each Member State shall recognize the diplomas, certificates and other evidence of formal qualifications in specialized medicine awarded to nationals of Member States by the other Member States in accordance with Articles 2, 3, and 4 and 8 of Directive No 75/363/EEC and which are listed in Article 5, by giving such qualifications the same effect in its territory as those which the Member State itself awards.

This Directive goes on to list the areas of specialty practice in the various Member States and, over the years since 1975, it has been updated to include the new Member States, of Greece, Spain and Portugal. It refers to all specialties which are practised in two or more Member States (Article 6). Such mutual recognition of diplomas is restricted to those Member States wherein the specialty is recognized.

The Directive goes on to acknowledge the need to accommodate existing circumstances (Article 9). For instance, recognition is given by certificate to those nationals whose qualifications in medicine did not satisfy all the new minimum training requirements laid down in the medical Directive $75 / 363 /$ EEC but who could produce a certificate 
indicating that they had effectively and lawfully been engaged in the activities in question for at least three consecutive years during the previous five years.

Other Articles in 75/362/EEC govern the use of academic titles (Article 10) and the provision of proof of good character (Article 11).

The other medical Directive (75/363/EEC) specifically addresses the matter of harmonization of standards both at undergraduate level and at the level of specialist training.

The key introductory paragraph here recognizes that medical practice is in the main specialized (at this stage general practice was not regarded as a specialty). It therefore begins by also recognizing the need for co-ordination of the requirements for postgraduate training in specialized medicine. It recognizes that certain minimum criteria should be laid down concerning the right to take up specialized training, e.g. satisfactory completion of undergraduate and pre-registration medical education, minimum training periods, methods by which such training is given and the places where it is to be carried out as well as the necessary supervision.

The matter of undergraduate education is addressed in Articles 1 and 2. There is a bare outline of the necessary and basic content of such training and a statement that it shall comprise at least a six-year course or 5500 hours of theoretical and practical instruction given in a university or under the supervision of a university. Article 3 concerns itself with part-time training. Over the years this has caused difficulties because in the UK we have a formal system for part-time training at a specialist level, mainly for married women. However, that has been sorted out. Articles 4 and 5 then importantly address the question of minimum length of specialized postgraduate training courses both for such specialist practice occurring in all Member States and for such practice recognized only within some of the Member States. As originally laid out these are as follows:

\section{All Member States (Article 4)}

Member States shall ensure that the minimum length of the specialized training courses mentioned below may not be less than the following:

\begin{tabular}{|c|c|}
\hline $\begin{array}{l}\text { - general surgery } \\
\text { - neuro-surgery } \\
\text { - internal medicine } \\
\text { - urology } \\
\text { - orthopaedics }\end{array}$ & five years \\
\hline $\begin{array}{l}\text { - gynaecology and obstetrics } \\
\text { - paediatrics } \\
\text { - pneumo-phthisiology }\end{array}$ & four years \\
\hline $\begin{array}{l}\text { - anaesthesiology and reanimation } \\
\text { - ophthalmology } \\
\text { - otorhinolaryngology }\end{array}$ & three years \\
\hline
\end{tabular}

\section{Some Member States (Article 5)}

Member States which have laid down provisions by law, regulation and administrative action in this field shall ensure that the minimum length of the specialized training courses mentioned below may not be less than the following:

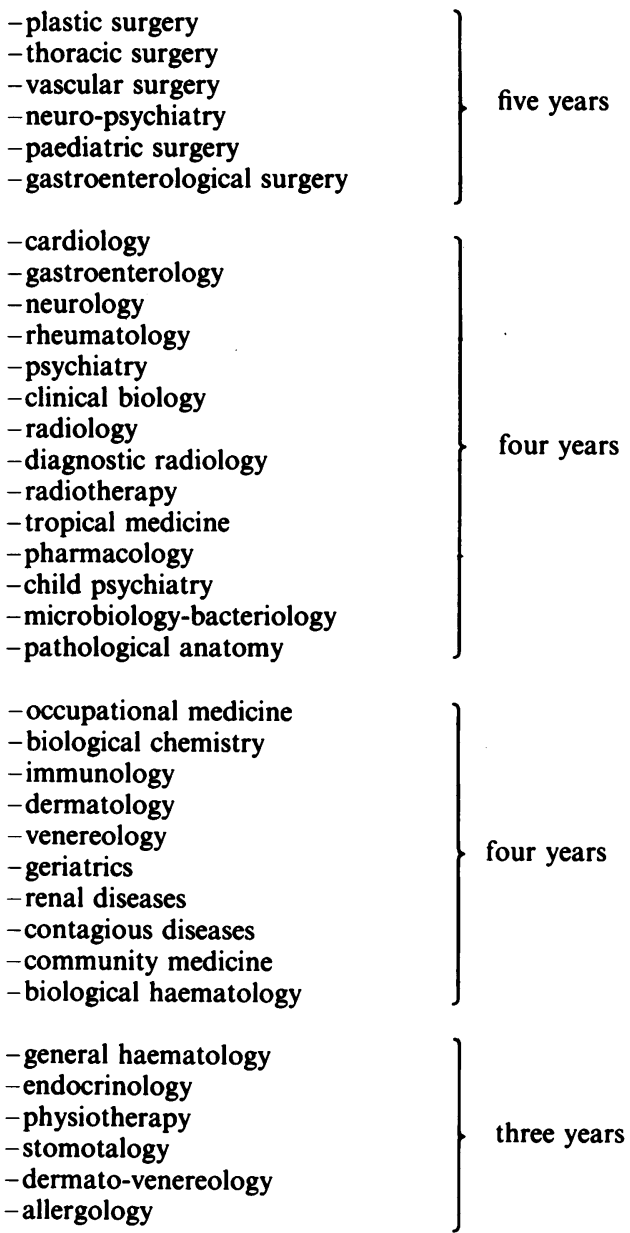

\section{The Advisory Committee on Medical Training} (ACMT), the first 10 years

These first two medical Directives were seminal. Similar Directives for nursing and dentistry very quickly followed. The working groups of doctors from the Member States who had helped draft the 1975 Medical Directives had expressed the view that the Commission would require an established Advisory Committee on Medical Training thereafter. In this way the present Advisory Committee was born in 1976. Others in allied fields were then also established. In many ways veterinary medicine can be taken as a paradigm over the subsequent years. The subject, being much smaller than medicine, has proved more manageable and a great 
deal of progress has been made. An illustration of this arises later in this paper. The Advisory Committee on Medical Training (ACMT) settled down to consider development and updating of the first two Medical Directives. Ten years after the publication of the first two Medical Directives the Committee undertook a formal review of its work of the previous nine years and the proceedings of the conference wherein this was undertaken and also made a systematic attempt to forecast the nature of medical practice in the twenty-first century have been published. ${ }^{3}$

The Conference was reminded ${ }^{5}$ that ACMT first met in April 1976 and, over the next nine years, had adopted a number of reports relating to the two Medical Directives. The principal ones are:

1. The general tendencies in basic medical education (1978).

The recommendations of this report were:

- The need to control and restrict numbers of medical students

-The essential integration during basic studies of practical with theoretical training

- The advantage of replacement of separate courses in independent disciplines by integrated education

-The necessity for freedom for universities to experiment with curricula and teaching methods, with provision for the exchange of results

- The need to promote self-education and optional courses

-The periodic re-examination of curricula

2. Opinion on the part-time training of specialists (1978)

3. Report and recommendations on the general problems of specialist training (1978)

This contained the following recommendations:

- A competent authority should be set up in each Member State to lay down training standards, enforce their application, validate them by awarding qualifications and ensure coordination between the various disciplines

-Specific training for specialists should begin after successful completion of basic training

- Number of candidates should be matched to the capacity of the training establishments

- Selection methods should be considered

-Full-time training should be remunerated

-Specific training should start in the form of extended general training of a common-trunk curriculum

- Care should be taken not to create new specialties unnecessarily

\section{Recommendation on the clinical training of doctors (1979)}

These were that:

- The core of essential knowledge and experience which the student should acquire by the end of his studies should be defined by the competent authorities

- Assessment and control methods should be devised to determine whether these aims and objectives have been achieved and, if necessary, to see how the training programmes should be modified

-The relationship between theoretical teaching and clinical experience should be kept under continual review

- Clinical training should cover the main disciplines and lead to a high level qualification and clinical competence

- Preclinical and clinical disciplines should be integrated into training

-New discoveries should be incorporated into courses and outdated material replaced, and students should be encouraged to pursue private study and take part in the improvement of the curriculum

-Student numbers must be brought into line with the available teaching and clinical facilities

- Each student's motivation and personal characteristics should be assessed; methods of assessment and selection might vary from one country to another

- Teacher training must be tailored to teaching methods and techniques, and ways devised for assessment of the teaching

-Optimum use must be made of teaching potential and an acceptable ratio sought between the number of students receiving clinical training and the number of teaching staff

- There should be early contact between students and patients

- Hospital medical staff and technical equipment should be of a high standard

-Not only teaching hospitals but also regional and local hospitals should be used for training

-Students should be brought into contact with the medical and social aspects of medicine in all places considered able to provide this kind of teaching.

5. Report and opinion on specific training for general practice (1979)

The Committee recommended that:

-Specific instruction in general medical practice be given after basic training

-Member States should promote such specific training

-General practice should be recognized as a specific discipline

- Periodic reports to the Commission be submitted by member states on progress in this area

6. Opinion on the mutual recognition of training periods completed in another Member State as part of specialist training courses (1981)

The Committee proposed the following:

-It should be possible to undergo part of the specialist training in one or more Member States

-Prior agreement of the authorities of the country of origin is necessary, subject to production of a document attesting to the training programme, the nature of the establishment and its organisational structure and the agreement of the authorities of the host country

-On his return, the trainee will produce a certificate from the supervising specialist, attesting to his activities 
-Channels of communication should be developed, specialty by specialty, between the competent authorities in the Member States for the purpose of exchanging lists of recognized training posts and answering specific enquiries

7. Report and recommendations on the problem of the balance between the number of medical students and the resources needed for their training (March 1981)

The recommendations are as follows:

- Measures should be taken in Member States to ensure and maintain comparably high levels of medical training

-Staffing norms should be introduced

-Student numbers and training facilities should be matched

- Account should be taken of the student's overall knowledge of and aptitude for the practice of medicine

- The ideal student/teacher ratio should be sought

- Assessments should be carried out at the end of studies to ensure uniform levels of training throughout the Member States

8. Opinion on the aims of basic medical training (1981)

This listed the abilities required for the practice of medicine.

9. Second report and recommendations on the training of specialists (1983)

These recommendations were as follows:

- The number of trainee specialists must be regulated on the basis of future needs for specialists and the available training resources, so as to ensure that the training is of a high standard

-To this end, use must be made of the practical training potential of posts in non-university hospitals and sometimes in non-hospital institutions

- Training should normally be full-time, with exceptions for part-time training. It should include theoretical training at the highest level and practical experience in appropriately remunerated service posts. Trainees should gradually be assigned an increasing measure of responsibility commensurate with their growing skills and experience.

- Training should include a common trunk in related specialties, the duration and content of which would be adapted to the intended ultimate specialisation

- All specialist training should be supervised by a competent authority approved to grant, or, where appropriate, withdraw approval of training establishments, account being taken of the hospital facilities, the activity of the unit and the qualifications and experience of the trainers and their colleagues

- The competent authority should ensure that the training given is of a high standard by prior approval of the training programme and supervision of trainees' performance by means of a report book, suitable examinations or assessments

- Whereas the minimum periods of training for the specialties referred to in the 1975 directive are already exceeded in most Member States, and whereas the duration of training courses should correspond to the training content which is really necessary in the present state of medical science, it should be for the competent national authorities to decide for themselves on the nature and timetable of any measures that may be necessary for the purpose of altering the duration of training courses in their respective countries

The report also contains a proposal on changes to the duration of training in the case of certain disciplines.

\section{Report on occupational medicine (1985)}

This specialty was identified as having developed rapidly but with radically different training programmes across Member States. The report recommended accepting it as a specialty and contains a number of proposals for harmonizing the training for it.

During this, the first nine-year period of office of the Committee, other new specialties such as fasciomaxillary surgery and nuclear medicine had also come to be recognized and listed in the Directives.

In his subsequent summary review of the impact of the two Directives and the Committee's reports up until 1985 Sorensen $^{6}$ drew attention to the concept of the common trunk of specialist training that had by then been recommended several times by the Committee and also the Committee's concern that there be required special postgraduate training for general medical practice as soon as possible. He doubted whether the overall impact of the Directives and the Committee's work was yet substantial and he identified some of the resistances to change. His emphasis on the need to protect and sometimes to reinforce the present common trunk of medical training, especially at postgraduate level, resonates with the increasing emphasis placed on this idea by other medical educationalists in the USA $^{2}$ and in the UK. ${ }^{4}$ I would add that these Reports reflect a constantly recurring concern of the Committee with the need not only to recommend but also to ensure that uniformly high standards of medical practice operate throughout the Community and also the Committee's awareness that such high standards are closely linked to control of the numbers of doctors in practice which in its turn is linked to the numbers of people initially admitted to medical studies.

The remainder of the 1985 Conference was devoted to an attempt to identify the direction that medical education should now take to prepare students and young doctors for practice in the next century. Some considered that this was an impossible task but it was evident that students starting their studies now would not become independent practitioners before the turn of the century and that therefore there was a real need to set them optimal and focused educational goals. ${ }^{7}$ Summarizing this 
part of the proceedings Castermans ${ }^{8}$ concluded that the following priority educational needs and been identified:

1. Solid clinical training accompanied by a rejuvenated curriculum including new knowledge and designed to train minds rather than pump them full of facts.

2. Enlightened training of the future doctor to assume all his responsibility either on his own or in a team by confronting him specifically with ethical problems such as he will be constantly encountering

3. Supplementary training in general medical practice and in specialized medicine, the characteristics of which will coincide closely with the recommendations of our Committee

4. Generalization of continuing education as a prerequisite for maintaining the quality of medical care.

I believe this list to be central to the maintenance and development of medical practice in the years ahead. To the first point I would add that such skills are importantly underwritten by a knowledge of anatomy ${ }^{9}$ and the skills for communication with all kinds of patients and colleagues within and across ethnic boundaries. ${ }^{8,10}$

The second point has preoccupied the Committee ever since, there being those on it who believe that recognition of the measures necessary to ensure the maintenance of defined ethical standards are the only realistic ones that can be undertaken in respect of the future. All else, they say, is unpredictable, subject to such events as the unexpected emergence of new disease, new technologies and new knowledge.

The third point, stressing the importance of ensuring high standards in general medical practice, emphasizes the centrality of primary care as well as, indirectly, the importance of the common trunk of postgraduate training for everyone.

The fourth point concerns the neglected area of the need to maintain high standards of practice other than by the debarring of those practitioners who palpably fail in this.

In 1985 the Committee also attempted formally to identify its priorities for the next decade (coincidental with this it found itself needing to defend its continued existence but persuaded the Commission that there was still work to be done!).

A working party of the Committee duly reported" that the new priorities should be as follows:

\section{PROPOSED FUTURE TASKS}

A. To strengthen the Committee's review procedures

(To date much reliance has been placed upon national groups within the Committee reporting back upon developments in their own countries; for instance, as regards changes in medical training and practice, or as regards the impact of reports and recommendations published by the Advisory Committee. The variation between and, in the case of some Member States, the total of absence of - the national reports required by the Committee for the 1985 review underlined the inconsistency of this system. If the Committee is to be correctly informed on matters fundamental to its task, its review procedures need to be strengthened).

B. To develop the techniques of evaluation (including selection) as part of the internal educational processes within schools.

(The Committee is currently considering a report - III/D/1643/4/83 - which deals with methods of assessment in basic training. This work needs to be built upon, because the issues go much wider than the scope of that report. Assessment in specialist training is another issue. But there are also the questions of initial selection for entry into medical studies and of selection of trainers. There is also the question of assessment of the outcome of medical training - the impact of the medical education process upon the recipients of it.)

\section{To develop continuing medical education}

(The attention this topic attracted at the Symposium reflects the increasing interest being shown in it in many countries, inside and outside the EC. With the rapid developments in medical science, it is linked with the ethical/moral obligation on doctors to keep themselves abreast of ideas and knowledge throughout their professional lives.)

D. To have a continuing awareness of new areas of development in medical practice and the need to monitor recent developments, e.g. occupational medicine, specific training in general medical practice

(Such developments, especially major ones like those in general practice, can have implications for training given elsewhere; for instance, on training that immediately precedes or follows the innovation. The impact may vary between Member States and could thus lead to a divergence of standards of training in the Community.)

\section{E. Specific subjects}

The following individual subjects were also considered to merit special attention, either as isolated topics or within wider programmes of study such as those listed above

- overloading of the undergraduate curriculum - undergraduate teachers being too specialized

-the need for doctors to develop problemsolving skills

- the continued importance of practical skills

-teaching the social and behavioural sciences

-the continuing refinement of the core curriculum 
- the teaching and understanding of ethical issues - the development of management skills (including an awareness of economic constraints)

- the involvement of the doctor more widely in health care systems

The working party concluded its Report with the following important footnote:

THE AD HOC WORKING GROUP WISHES TO CONVEY TO THE MAIN COMMITTEE ITS SPECIAL CONCERN ABOUT THE HAZARDS TO TRAINING STANDARDS POSED BY EXCESSIVE NUMBERS OF STUDENTS. THIS PROBLEM IS PARTICULARLY ACUTE IN THOSE COUNTRIES WITHOUT NUMERUS CLAUSUS.

In June 1985 the Commission produced a White Paper addressing the matter of the completion of the European internal market. The document dwelt on the need for the complete removal of physical, technical and fiscal barriers and set 1992 as the target. It construed the freedom to provide services within the Community as being dealt with within the rubric of removal of technical barriers. Paragraph 88 of the White Paper states:

The Commission considers it crucial that the obstacles that still exist within the Community to free movement for the self-employed and employees be removed by 1992. It considers that Community citizens should be free to engage in their professions throughout the Community, if they so wish, without the obligation to adhere to formalities which, in the final analysis, could serve to discourage such movement.

Since the publication of the White Paper the Member States have met and enshrined many such objectives within the Single European Treaty (1988).

\section{ACMT since 1985}

As a result of the Committee's advice a third Medical Directive (86/457/EEC) was eventually produced on the 15th September 1986. The rationale for this was contained in a series of important introductory paragraphs, the three main ones of which are as follows:

Whereas the point has now been reached where it is almost universally recognized that there is a need for specific training for the general medical practitioner to enable him better to fulfil his function; whereas this function, which depends to a great extent on the doctor's personal knowledge of his patient's environment, consists of giving advice on the prevention of illness and on the protection of the patient's general health, besides giving appropriate treatment;

Whereas this need for specific training in general medical practice has emerged mainly as a result of the development of medical science, which has increas- ingly widened the gap between medical research and teaching on the one hand and general medical practice on the other, so that important aspects of general medical practice can no longer be taught in a satisfactory manner within the framework of the Member States' current basic medical training.

Whereas, apart from the benefit to patients, it is also recognized that improved training for the specific function of general medical practitioner would contribute to an improvement in health care, particularly by developing a more selective approach to the consultation of specialists, use of laboratories and other highly specialized establishments and equipment.

The Directive goes on under Article 2 to identify the minimum requirements for training in general practice:

1. The specific training in general medical practice referred to in Article 1 must meet the following minimum requirements:

(a) entry (into training) shall be conditional upon the successful completion of at least six years' study within the framework of the training course referred to in Article 1 of Directive 73/363/EEC;

(b) it (training) shall be a full-time course lasting at least two years, and shall be supervised by the competent authorities or bodies;

(c) it (training) shall be practically rather than theoretically based; the practical instruction shall be given, on the one hand, for at least six months in an approved hospital or clinic with suitable equipment and services and, on the other hand, for at least six months in an approved general medical practice or in an approved centre where doctors provide primary care; it shall be carried out in contact with other health establisments or structures concerned with general medical practice; however, without prejudice to the aforesaid minimum periods, the practical instruction may be given for a maximum period of six months in other approved health establishments or structures concerned with general medical practice;

(d) it (training) shall entail the personal participation of the trainee in the professional activities and responsibilities of the persons with whom he works.

As with the second Medical Directive there is a qualifying paragraph within Article 7 which allows the certification of doctors as being trained within the spirit of the Directive if they have been established in practice for some years and without the need now for them to undertake such a formal retraining.

With this achieved (though many on the Committee believed that a three-year period of postgraduate training for general practice would have been appropriate) the Committee decided to under- 
take two new main tasks. One working party was set up to examine and report on the quality of training in the Community in relation to the numbers of medical students. A second working party was set up to report on what could be foreseen as being the future role of the doctor. The Committee's attention was also drawn by the Commission to the Community's concerns about preventive approaches to disease with particular reference to cancer and for the need for doctors to be conversant with this area. Another working party was therefore also set up to examine this matter and has since reported (III/D/2111/87-EN).

\section{Future role of the doctor}

The working party convened to consider the future role of the doctor in medical practice has not yet reported. It has available to it the views of the 1985 working party ${ }^{11}$ (III/D/1570/85-EN) on the matter which were that the doctor would continue to have a core role based on consultation skills coupled with a management role and with the need to maintain his or her standards of knowledge and skill within the framework of proper professional attitudes. In detail these roles and attributes were identified as follows:

\section{A. CORE ROLE}

1. To occupy a central role in terms of understanding the structure and function of the human body and mind in its interaction with the social and physical environment in health and illness, and with the function of alleviating distress and illness when possible.

2. Recognition of the central importance to this task of the totality of consultation skills, including clinical skills, the skill of history taking and of communication in general; and also an understanding of health-related behaviour, the social situation of the patients and the societal support systems available.

3. Recognition that one's role is also important in relation to the treatment and management of chronic disability, including rehabilitation; also in the care of the terminally ill.

4. Contributing to the prevention of illness and to the promotion of health.

B. MANAGEMENT ROLE

5. The ability to work within a team, and as a team leader.

6. The development and deployment of administrative and planning abilities.

\section{CONTINUING EDUCATION}

7. The ability to assess one's own performance critically and to permit its assessment by others.
8. Keeping oneself up-to-date and highly capable in relation to new knowledge and skills and contributing to the promulgation of knowledge.

\section{ATTITUDES/ETHICS}

9. The development and maintenance of proper attitudes appropriate to a high level of professional performance.

10. The ability to recognize and think clearly through ethical problems in such a way as to enable the patient and the doctor to reach informed decisions.

\section{E. SPECIALIZED ROLES}

11. i.e. Subsequent to core training, and in the relevant clinical, administrative or laboratory fields.

The present concerns of this working party have been referred to earlier and have to do with the emphasis that should be placed on the role of the doctor in respect of ethical issues and whether or not the main statement should be restricted to his responsibility for relieving distress and preserving life under all circumstances.

\section{Numerus clausus and medical manpower}

The working party concerned with the numerus clausus issue reported in 1988 (III/D/331/3/87-EN) within a document entitled Report on quality of training. It had begun by identifying the present numbers of students admitted to medical school each year and the number of doctors graduating each year from the Member States. These findings are displayed below in Tables I and II respectively.

The working party noted a number of trends within the data as follows:

1. The United Kingdom, where the situation is stable, with a small number of students admitted and qualified doctors emerging per annum (appproximately $1 / 15,000$ of the population per annum). The second characteristic is the very low rate of failure over the training period. This observation confirms the finding in report III/D/ $234 / 4 / 80$ that medical training in that country holds a privileged position. Even if it is not proved that the severe restrictions on access to medical studies in the United Kingdom were originally introduced for docimological reasons, it has to be said that they and the stability they produce have enabled training resources to be adapted as efficiently as possible to the numbers selected.

2. A second trend is represented by three Member States: France, the Netherlands and Portugal, which have adopted policies of increasing restrictions on access to medical studies and are now approaching the same ratio of one newly qualified doctor per annum to 15,000 inhabitants; if these meaures are kept France and 
Table I Number of students admitted to the 1st year of medicine

\begin{tabular}{|c|c|c|c|c|c|c|c|c|c|c|c|c|c|}
\hline \multirow[b]{3}{*}{ *Belgium } & \multirow{3}{*}{ 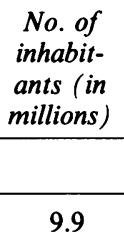 } & \multicolumn{12}{|c|}{ Number of students } \\
\hline & & \multicolumn{2}{|c|}{1972} & \multicolumn{2}{|c|}{1978} & \multicolumn{2}{|c|}{1984} & \multicolumn{2}{|c|}{1985} & \multicolumn{2}{|c|}{1986} & \multicolumn{2}{|c|}{1987} \\
\hline & & 4705 & (2093) & 3274 & (2645) & 2791 & (3529) & 2773 & $(3552)$ & 2533 & $(3604)$ & - & - \\
\hline Denmark & 5.1 & 1611 & (3140) & 855 & (5918) & 653 & (7840) & 569 & (8998) & 539 & (9449) & 526 & (973? \\
\hline W Germany & 61.8 & 5728 & (10791) & 10326 & (5988) & 11962 & (5169) & 11531 & - & 11531 & - & 11614 & - \\
\hline Greece & 10.0 & - & - & - & - & 1384 & $(7225)$ & 1530 & $(6509)$ & 1188 & (8383) & - & - \\
\hline Snain & 37.7 & 13547 & (2783) & 11454 & (3291) & 6362 & - & - & - & 6000 & (6283) & 4950 & $(761$ \\
\hline nce & 56.5 & 8652 & (6095) & 7913 & (6664) & 5000( & (10966) & 4754 & (11863) & 4550 & (12395) & 4400 & $(1281$ \\
\hline Ireland & 3.2 & 507 & (6167) & 492 & (6544) & 471 & $(6623)$ & 446 & (6995) & 431 & $(7238)$ & - & - \\
\hline *Ital & 57.1 & 30805 & (1812) & 26738 & (2087) & 14904 & $(3830)$ & 12305 & (4649) & 10943 & (5235) & 9418 & $(607$ \\
\hline *Luxembourg & 0.4 & 51 & - & 74 & - & 54 & - & - & - & - & - & - & - \\
\hline Holland & 14.6 & 1690 & $(8082)$ & 1900 & (7189) & 1457 & (9972) & 1474 & (9857) & 1463 & (9931) & 1432 & - \\
\hline Por & 10. & 2013 & $(4290)$ & 1185 & $(8109)$ & 641( & (15801) & 383 & (26446) & 342 & (29616) & 239 & $(4238$ \\
\hline UK & 55.8 & 3488 & (15992) & 3877 & (14387) & 3966 & (14065) & 3938 & (14164) & 3967 & (14061) & - & - \\
\hline
\end{tabular}

Derived from EEC Advisory Committee on Medical Training Report III/D/331/3/89-EN, ${ }^{*}$ No selection at admission to the 1 st year of medicine. ${ }^{* *}$ Selection operates in 2 nd year. Figures in brackets $=$ number of inhabitants per student or doctor.

Table II Number of doctors graduated

\begin{tabular}{|c|c|c|c|c|c|c|c|c|c|c|c|}
\hline & $\begin{array}{l}\text { No. of } \\
\text { inhabit- } \\
\text { ants (in } \\
\text { millions) }\end{array}$ & \multicolumn{10}{|c|}{ Number of doctors } \\
\hline & & \multicolumn{2}{|c|}{1979} & \multicolumn{2}{|c|}{1984} & \multicolumn{2}{|c|}{1985} & \multicolumn{2}{|c|}{1986} & \multicolumn{2}{|c|}{1987} \\
\hline Belgium & 9.9 & 1499 & (6571) & 1519 & (6484) & 1432 & (6783) & 1366 & $(7210)$ & - & - \\
\hline Denmark & 5.1 & 668 & (7575) & 707 & (7242) & 663 & (7722) & 560 & (9142) & 559 & (9159) \\
\hline W Germany & 61.8 & 7333 & (9631) & 9470 & (6529) & 9534 & - & 10618 & - & 9936 & - \\
\hline Greece & 10.0 & 1108 & (9025) & 1504 & (6642) & 849 & (11731) & 1154 & (8630) & - & - \\
\hline Spain & 37.7 & 7497 & (5028) & 10346 & (3644) & - & - & - & - & - & - \\
\hline France & 56.5 & 8687 & (6071) & 8577 & (6392) & $?$ & - & 16350 & for the tw & o years & 6 and 87 \\
\hline Ireland & 3.2 & 481 & (6486) & 477 & (6541) & 481 & (6486) & 477 & $(6540)$ & - & - \\
\hline Italy & 57.1 & 14264 & (4010) & 14044 & (4072) & 13079 & (4373) & 13053 & (4382) & - & - \\
\hline Luxembourg & 0.4 & 39 & - & 24 & - & - & - & - & - & - & - \\
\hline Holland & 14.6 & 1461 & (9945) & 1485 & (9693) & 1474 & (9857) & 1746 & (8321) & - & - \\
\hline Portugal & 10.3 & 1439 & (6678) & 904 & (11205) & 859 & (11791) & 884 & $(11458)$ & - & - \\
\hline UK & 55.8 & 3387 & (16469) & 3498 & (15946) & 3483 & (16014) & 3610 & $(15451)$ & - & - \\
\hline
\end{tabular}

Derived from EEC Advisory Committee on Medical Training Report III/D/331/3/87-EN

Portugal should reach this level in a few years and could go beyond it.

3. A third trend emerges in Belgium, Denmark, Germany, Greece and Ireland, where the number of students and newly qualified doctors per annum remains high (between 1:6,000 and 1:9,000 in the case of the latter). A confirmed tendency to a slow reduction of numbers can be seen.

4. A special situation is known in Spain where during 15 years the number admitted has been reduced to $1 / 3$ of what it used to be. These measures are too recent to have an important impact until now on student population in clinical studies and number of graduates. Persisting on this course should place Spain into the second group.

5. Italy represents the last trend. In spite of a spontaneous reduction in the number of entries into medical training almost no reduction in the number of graduates can be seen. The number of inhabitants per newly qualified doctor is clearly much lower than in other Member States and nothing suggests that the situation will improve 
here. The Advisory Committee is concerned about the continuing Italian situation with its vulnerable level of medical training. It seems very unlikely that this Member State can envisage any increase in the resources as the number of patients as well as the budgetary resources are limited everywhere. During discussion of this report, the Committee was informed that Italy had just taken measures designed to reduce the number of students.

The Committee was concerned about a number of factors including the loss of traditional and valuable small group and bedside apprenticeship teaching opportunities and the unavailability of patients for very large numbers of medical students needing to learn their consultation skills (for instance, in the UK we are familiar with requests from medical students from some other Member States wishing to undertake extended clinical electives in the UK and wherein it would seem that there are sometimes not sufficient opportunities for them in their own country) and also the likely numbers of unemployed doctors under such circumstances whose consultation skills would diminish through lack of practice. The working party's recommendations were as follows:

The most realistic method of matching training resources to the number of students admitted to medical studies, and thus of ensuring a comparably high level of the latter, is to tighten controls on the numbers admitted. The desirable situation achieved or being achieved by four Member States is given as an example, with reference to the total population of the country in question as an approximate estimate of training resources. The ratio in these Member States is about one qualified doctor to 15,000 inhabitants per annum.

The conclusions of the 'report and recommendations' adopted in 1981 are still applicable, and the present conclusions should be regarded as supplementing the report (doc. III/D/230/4/80).

The restrictions on the number of students admitted should be accompanied by a selection process which sifts out those most likely to become doctors, taking the wide range of medical activities into account.

The Advisory Committee would request the Commission to ensure that the national laws adopted in compliance with Directive $86 / 457 /$ EEC are implemented in each Member State in accordance with the time limits laid down therein

It would draw attention to the adverse effects of an imbalance which could develop as between the number of places for training in general medical practice and the numbers of applicants for such training. This could give rise to groups of doctors having no access to training, that is, being prevented from pursuing their professions. This matter may require further consideration in the light of more experience of the operation of Directive 86/457/EEC.
Motivation must be the driving force behind the choice of this specific branch. Its pursuit must therefore be as attractive as that of specialized medicine.

The Committee recommends that the definition of training places and the appointment and training of supervisors of training in general medical practice should satisfy criteria that are just as strict as those applied to specialist training; they should be placed under the responsibility of bodies that include representatives from the faculties of medicine, the professions concerned and the competent authority.

It recommends that the checks on knowledge should be identical in quality to those on specialized training and guarantee a comparably high level of training in all the Member States.

This report and these recommendations were adopted unanimously by the Committee on 5 October 1988 with 23 (1) votes in favour; 13 (2) members were absent and not represented.

This report and these recommendations are addressed to the Commission and the Member States and will be forwarded to them after having been confirmed in all Community language versions by the Committee by written procedure.

It will be seen that the working party was addressing the problem of numerus clausus from the standpoint of quality of training and quality of care. A number of the recommendations focus on the problem within general practice. Up until the 1986 Directive on the need for training for general practice, it was likely that the majority of excess doctors had settled into such general practice without further training. In the future this would not be possible.

This cautionary tale about the Committee's concerns with manpower would not be complete without acknowledging the recent article in the New England Journal of Medicine $e^{12}$ and the attendant leading article in that journal. ${ }^{13}$ There the alternative case is cogently argued, that there will be a shortage of doctors in 20 years' time. However, perhaps the best indicator that we have is that of manpower planning in the UK where the majority of the population receives care within the National Health Service. As previously indicated the steady number of graduates of about 4000 per annum for a population of about 55 million is clearly about the right number needed to staff that service. There should undoubtedly be more consultants in that system and they will be especially needed in the future now that there are fewer overseas doctors to man the on-call service but this unlikely to lead to a need for a greater number of medical students. The major task, as always, is to ensure that people of the right calibre and motivation are recruited in the first instance so that wastage is minimal. 


\section{Future tasks}

There are clearly many future tasks for the Advisory Committee to address and some of them have been spelled out above (ACMT Report III/D/1570/85-EN, Annexe 3). An important one is how to establish in an acceptable way the mutual assessment of each other's standards of education so that we can truly learn from and help each other. A system of external examining has been standard practice in the UK for many years ${ }^{14}$ but is not a widespread formal custom elsewhere and I find it is strongly resisted by the representatives of some Member States on the ACMT. The Advisory Committee on Veterinary Training to the EEC has issued a relevant report (III/D/1656/7/83-EN) in May 1985, Report and Recommendations to ensure a comparably high standard of Veterinary Training in the Community. It makes excellent reading. It argues the cases, as would be true for medicine, for (A) a relatively rich staff/student ratio and (B) a procedure of mutual evaluation as the basis for high standards. Specifically, its recommendations are:

1. The adoption of $5: 1$ as the target figure for the overall student: teaching staff ratio for veterinary schools. The ratio for paraclinical and clinical studies would be narrower and that for preclinical studies wider.

2. The adoption of a range between $2: 1$ and 2:5:1 as the support staff : teaching staff ratio.

3. The determination of the minimum number of teachers (or their full-time equivalents) necessary to cover all subjects listed in the annex to Directive 78/1027/EEC.

4. The determination, where possible, of a financial weighting for the annual cost of veterinary sciences compared with non-laboratory-based courses.

5. The adoption of a procedure of evaluation based on a self-evaluation by each school backed by an advisory visit along the lines of the framework illustrated in the report.

6. Proceeding to a trial of this procedure, financed by the Community.

It is relatively easy in veterinary medicine because, as has already been said, it is a much smaller subject than medicine itself but, as I have also indicated earlier, the veterinarians may be showing us the way ahead. Consequently in their 1985 Report the Advisory Committee on Veterinary Training is about to conclude a pilot study of reciprocal visits of its members between Member States and which I understand has been found to be constructive and widely welcomed even by those Schools of Veterinary Medicine which were regarded during the visits as displaying poor standards in certain respects. It could be that a pilot system involving exchange of examiners between medical schools in Member States who wished to engage in this process could be financed by ERASMUS, at least in the form of a pilot study.

\section{Is movement occurring?}

Finally, this whole concern has to do with the free movement of professionals within Europe. I cannot tell you how that movement is occurring throughout the Community but you may be interested to see the figures in respect of graduates from other Member States who are now registered to practice in the UK. These data are outlined in Tables III and IV from which you can see that the numbers registering are increasing rapidly. The concept therefore seems to be becoming a reality for Medicine. With the three Medical Directives well established and buttressed by an increasing number of reports and recommendations from the ACMT it would seem that our subject has anticipated the

Table III Numbers of doctors who had qualified in a Member State other than the UK who have been granted full registration in the UK

\begin{tabular}{cc}
\hline Year & No. of Doctors \\
\hline 1977 & 85 \\
1978 & 109 \\
1979 & 124 \\
1980 & 134 \\
1981 & 184 \\
1982 & 264 \\
1983 & 327 \\
1984 & 302 \\
1985 & 332 \\
1986 & 445 \\
1987 & 995 \\
1988 & 1309 \\
\hline
\end{tabular}

Table IV These doctors held qualifications granted in the following Member States

\begin{tabular}{lc}
\hline Country & No. of doctors \\
\hline Belgium & 301 \\
Denmark & 83 \\
France & 189 \\
Germany & 1029 \\
Greece & 851 \\
Ireland & 659 \\
Italy & 690 \\
Netherlands & 549 \\
Portugal & 46 \\
Spain & 213 \\
\hline
\end{tabular}


1992 threshold such that there will not need to be any further major Medical Directives in order to achieve the Community's new goals at that point.

\section{References}

1. Seche, J.-C. A Guide to working in a Europe without Frontiers. Commission of the European Communities, Luxembourg. 1988.

2. Association of American Medical Colleges GPEP Report. A 3-year review of the general professional education of the physician and college preparation for medicine. 1984.

3. Commission of the European Communities. Medical Training in the European Community. Springer-Verlag, Berlin, 1987.

4. Education Committee, General Medical Council. Recommendation on the Training of Specialists - issued in pursuance of Section 15 of the Medical Act 1978, October 1987, General Medical Council, London.

5. Pouyard, P. The impact of the directives and of the work of the Advisory Committee on Medical Training in the European Community. In: Medical Training in the European Community. Commission of the European Communities. Springer-Verlag, Berlin, 1987, pp. 5-11.

6. Sorensen, B. The impact of the directives and of the work of the Advisory Committee on Medical Training in the European Community. In: Medical Training in the European Community. Commission of the European Communities. Springer-Verlag, Berlin, 1987, pp. 12-16.

7. Crisp, A.H. Marrying medical education to the medical needs of the European Economic Community in the twenty-first century (Introductory Address, 19 June 1985). In: Medical Training in the European Community. Commission of the European Communities. Springer-Verlag, Berlin. 1987 pp. $17-18$
The requirements for 1992 set out in paragraph 88 of the Commission's 1985 White Paper have already largely been met.

8. Castermans, A. Summary and Conclusions. In: Medical Training in the European Community. Commission of the European Communities. Springer-Verlag, Berlin, 1987, pp. 72-75.

9. Crisp, A.H. The relevance of anatomy and morbid anatomy for medical practice and hence for postgraduate and continuing medical education of doctors. Postgrad Med J 1989, 65: 221-223.

10. Crisp, A.H. \& Edwards, W.J. Communication in medical practice across ethnic boundaries. Postgrad Med J 1989, 65: $150-155$.

11. Advisory Committee on Medical Training. Report of ad hoc working group on the future programme and working methods of the Advisory Committee. Commission of the European Communities. III/D/1570/85-EN, 1985.

12. Schwartz, W.B., Sloan, F.A. \& Mendelson, D.N. Why will there be little or no physician surplus between now and the year 2000? N Engl J Med 1988, 318: 892-897.

13. Schloss, E.P. Beyond GMENAC - another physician shortage from 2010 to 2030? N Engl J Med 1988, 318: 920-922.

14. Committee of Vice Chancellors and Principals. Academic Standards in Universities. Universities' methods and procedures for maintaining and monitoring academic standards in the content of their courses and in the quality of their teaching. July 1986.

15. General Medical Council. Annual Report for 1988. Geners Medicine Council, London. March 1989. 